\title{
Der Mundschutz als Lifestyle-Objekt
}

\section{Peter Engelhardt}

Prof. Dr. med., SVA Aargau

Wenn es vergleichsweise zum «Wort des Jahres 2020» so etwas wie den «Gegenstand des Jahres» geben wird, dann hat die Schutzmaske zweifelsohne das Zeug, dank Corona zum Symbol des Jahres 2020 zu werden. Auf den Strassen der Welt ist das Textil zu einem Accessoire geworden, wurde erst Kult und dann Sammlerobjekt. Ein Sammlerobjekt erst seit heute? Nein, schon seit Jahrzehnten. Darf ich Ihnen meine Kollektion exklusiver Schutzmasken vorstellen?

Diese von mir gesammelten Hygieneprodukte haben eine enge Beziehung zum Ausnahmeoperateur Prof. Maurice E. Müller (MEM), der sich nicht mit der hergebrachten Gesichtsverhüllung zufriedengab.

\section{Maurice E. Müller - der Übervater}

Wer noch Memorabiles von oder über Prof. M. E. Müller einer sich im Aufbau befindliche Sammlung zur Verfügung stellen möchte, wendet sich bitte an folgende Adresse:

Prof. Dr. Peter Ochsner Rüttigasse 7

CH-4402 Frenkendorf peter.ochsner[at]hin.ch

peter.engelhardt[at]sva-ag.ch
Rückblick in das Jahr 1989. Maurice E. Müller, emeritierter Professor der Orthopädie an der Universität Bern, erhielt die Ehrendoktorwürde der Universität Heidelberg. Wohl wurde hier ein weltberühmter Arzt, Lehrer und Forscher geehrt, sein weit gefächertes Curriculum war jedoch nicht allen Anwesenden bekannt. So lag es an mir, dem langjährigen Schüler und Verehrer des operativen Tausendsassas, Maurice Müller den Anwesenden vorzustellen. Das gesamte Leben

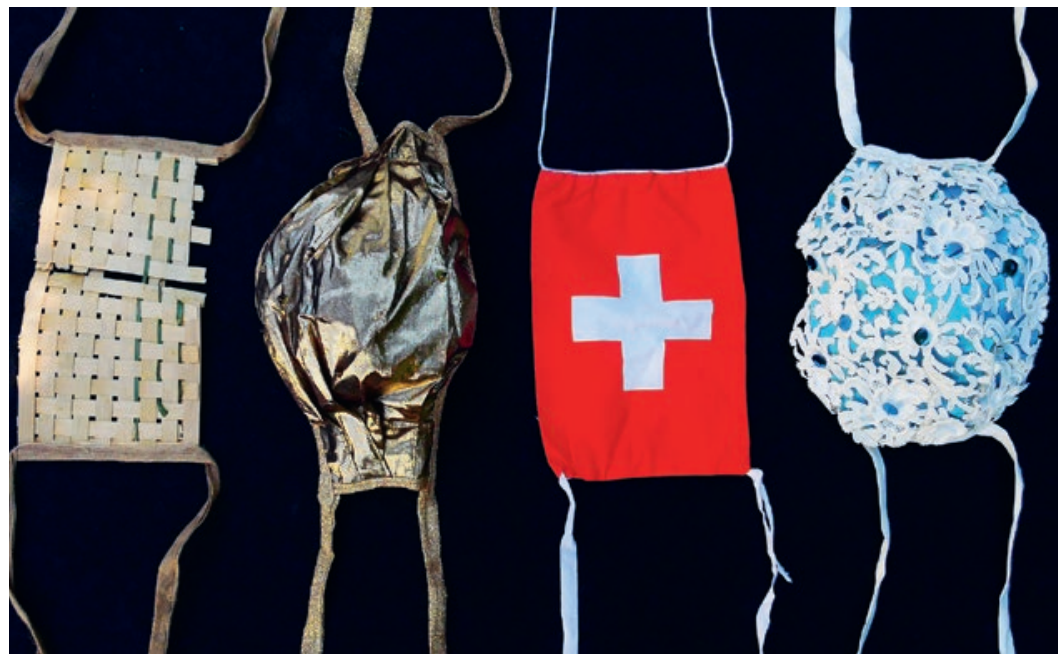

Exquisite Sammlung: Maurice E. Müller «benutzte» sie lange vor Corona! von MEM war mitgeprägt durch den Operationssaal, und dieser stand nicht nur in Bern. Entsprechend vielgestaltig war das Outfit des Operateurs und natürlich auch die jeweils getragene Schutzmaske. Jede Maske steht für eine Geschichte im Leben von Prof. Müller. Da ist der Mundschutz aus Bast: 1948 war der junge Chirurg in Äthiopien ... Natürlich, Sterilität im Operationssaal! Auch an diesem Ort konnte sie mit Hilfe ortsüblicher Materialien garantiert werden. Die Maske musste eine besondere Ausstrahlung gehabt haben, denn ungefähr zu dem Zeitpunkt, als sie in Gebrauch war, wurde eine lebenslang währende Ehe begründet. «Schweizer Professor operiert reichsten Mann der Welt.» Was im Blick vom 9.3.1977 nicht zu lesen war: Der Mundschutz war nicht aus profanem Papier, sondern als Referenz an König Ibn Saud von Saudi-Arabien aus golddurchwirktem Textil gefertigt. Die Nebenkosten müssen gewaltig gewesen sein. Maurice Müller war dann in seinem Element, wenn internationale Gäste den OP bevölkerten. Er gab mit seinem präparierten Mundschutz ein klares Signal, wo der Swiss Champion zu finden war. Über 100 Kurse mit unterschiedlichen Themen aus der Orthopädischen Chirurgie wurden im Zentrum MEM in Bern im Laufe der Jahre angeboten und haben seinem Gründer internationalen Ruhm eingebracht.

Ein absoluter Reisser in meiner Sammlung an Mundmasken von Maurice Müller ist diejenige aus St.Gallen. In der Hochburg der Schweizer Spitzenindustrie hat Maurice Müller vor 70 Jahren die Orthopädische Chirurgie zur Kunst erhoben. Dem Inaugurator vieler bahnbrechender Methoden und Prinzipien der modernen Orthopädie und Traumatologie wurde ein Exemplar des Gesichtsornates aus St. Galler Spitze am 11. Oktober 1989, dem Tag der Würdigung als Ehrendoktor in Heidelberg, überreicht.

Es hat 30 Jahre gedauert, bis Schutzmasken im Jahre 2020 auch in Europa Lifestyle-Objekte wurden. Prof. Maurice E. Müller war hierbei, wie in vielen Bereichen des Medizinbetriebes, seiner Zeit weit voraus.

Bildnachweis

Privataufnahme Prof. Dr. med. Peter Engelhardt 